\section{(6) OPEN ACCESS}

\title{
Year-to-year variability in haemoglobin mass response to two altitude training camps
}

\author{
Blake D McLean, ${ }^{1,2}$ David Buttifant, ${ }^{1,2}$ Christopher J Gore, ${ }^{3,4}$ Kevin White, $^{1}$ \\ Justin Kemp ${ }^{2}$
}

${ }^{1}$ Sport Science Department, Collingwood Football Club, Melbourne, Victoria, Australia ${ }^{2}$ School of Exercise Science, Australian Catholic University, Melbourne, Victoria, Australia ${ }^{3}$ Department of Physiology, Australian Institute of Sport, Canberra, Australian Capital Territory, Australia

${ }^{4}$ Exercise Physiology Laboratory, Flinders University of South Australia, Bedford Park, South Australia, Australia

\section{Correspondence to} Blake McLean, Collingwood Football Club/Australian Catholic University, Locked Bag 4115, Fitzroy, MDC, VIC 3165, Australia; BlakeM@collingwoodfc.com.au

Accepted 11 September 2013

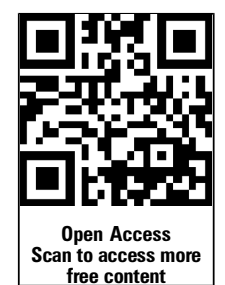

To cite: McLean BD, Buttifant D, Gore CJ, et al. Br J Sports Med 2013:47: i51-i58.

\section{ABSTRACT}

Aim To quantify the year-to-year variability of altitudeinduced changes in haemoglobin mass $\left(\mathrm{Hb}_{\text {mass }}\right)$ in elite team-sport athletes.

Methods 12 Australian-Footballers completed a 19-day (ALT1) and 18-day (ALT2) moderate altitude $(\sim 2100 \mathrm{~m})$, training camp separated by 12 months. An additional 20 participants completed only one of the two training camps (ALT1 additional $n=9$, ALT2 additional $\mathrm{n}=11$ ). Total $\mathrm{Hb}_{\text {mass }}$ was assessed using carbon monoxide rebreathing before (PRE), after (POST ${ }_{1}$ ) and 4 weeks after each camp. The typical error of $\mathrm{Hb}_{\text {mass }}$ for the pooled data of all 32 participants was $2.6 \%$. A contemporary statistics analysis was used with the smallest worthwhile change set to $2 \%$ for $\mathrm{Hb}_{\text {mass }}$. Results POST ${ }_{1} \mathrm{Hb}_{\text {mass }}$ was very likely increased in ALT1 $(3.6 \pm 1.6 \%, n=19$; mean $\pm \sim 90 \mathrm{CL}$ ) as well as ALT2 $(4.4 \pm 1.3 \%, n=23)$ with an individual responsiveness of $1.3 \%$ and $2.2 \%$, respectively. There was a small correlation between ALT1 and ALT2 ( $R=0.21, p=0.59)$ for a change in $\mathrm{Hb}_{\text {mass, }}$, but a moderately inverse relationship between the change in $\mathrm{Hb}_{\text {mass }}$ and initial relative $\mathrm{Hb}_{\text {mass }}(\mathrm{g} / \mathrm{kg}(\mathrm{R}=-0.51, \mathrm{p}=0.04))$.

Conclusions Two preseason moderate altitude camps 1 year apart yielded a similar (4\%) mean increase in $\mathrm{Hb}_{\text {mass }}$ of elite footballers, with an individual responsiveness of approximately half the group mean effect, indicating that most players gained benefit. Nevertheless, the same individuals generally did not change their $\mathrm{Hb}_{\text {mass }}$ consistently from year to year. Thus, a 'responder' or 'non-responder' to altitude for $\mathrm{Hb}_{\text {mass }}$ does not appear to be a fixed trait.

\section{INTRODUCTION}

High variability in physiological and performance responses exists between individuals following live high, train high (LHTH) and live high, train low (LHTL) altitude training. It has been proposed that some individuals respond better than others, possibly due to inherent genetic traits, and that 'responders' and 'non-responders' might explain the high-variability in adaptations to altitude training. ${ }^{1-5}$ Indeed, Chapman $\mathrm{et} \mathrm{al}^{4}$ retrospectively classified a group of distance runners as 'responders' or 'non-responders', based on their change in $5000 \mathrm{~m}$ time trial performance, following 28 days of LHTL. These authors ${ }^{4}$ reported that athletes who improved their time trial also exhibited the greatest erythropoietin (EPO) response and subsequent changes in red cell volume and $\mathrm{VO}_{2 \max }$.

If the classification of 'responder' and 'nonresponder' is a fixed trait, possibly related to underlying genetics, individual athletes should respond similarly whenever undergoing altitude exposure of similar duration and altitude. Only two studies until now ${ }^{3} 5$ have investigated the repeatability of responses to altitude. Robertson et $a l^{3}$ followed eight highly-trained runners during two blocks of hypoxic exposure (3 weeks LHTL), separated by a 5 -week washout period, and reported reproducible group mean increases for $\mathrm{VO}_{2 \max }(\sim 2.1 \%)$ and haemoglobin mass $\left(\mathrm{Hb}_{\text {mass }}(\sim 2.7 \%)\right)$, but not for mean changes in time trial performance $(+0.5 \%$ and $-0.7 \%$ following exposures 1 and 2, respectively). Moreover, there was a moderate but unclear negative correlation for change in $\mathrm{Hb}_{\text {mass }}$ from one exposure to the next, ${ }^{3}$ demonstrating high variability in individual responsiveness between exposures. Similarly, Wachsmuth $e t a l^{5}$ reported a weak correlation $(\mathrm{r}=0.379, \quad \mathrm{p}=0.160)$ between $\mathrm{Hb}_{\text {mass }}$ responses following two altitude training camps conducted approximately 3 months apart with elite swimmers, despite very reproducible increases in serum EPO $(\mathrm{R}=0.95, \mathrm{p}<0.001)$.

Team-sport athletes often complete preseason altitude training camps in an attempt to optimise running performance and we recently reported improved running performance $(\sim 1.5 \%$ above matched sea level control) accompanied by a $3.6 \%$ increase in $\mathrm{Hb}_{\text {mass }}$ following 19 days of LHTH in elite team-sport athletes. ${ }^{6}$ Similar to previous investigations, ${ }^{12}$ we reported high variability in erythropoietic responses, which may be partially explained by levels of initial $\mathrm{Hb}_{\text {mass }}{ }^{7}$; however, much of this variability remains unexplained. The possible identification of 'responders' and 'non-responders' after a single altitude training camp, or after an acute hypoxic exposure, may allow prescription of altitude training to be targeted towards those athletes who 'respond' well, and/or alternative methods/altitudes adopted in an attempt to enhance the response of potential 'non-responders'.

Therefore, the primary aim of this study was to examine the variability of physiological responses between two similar LHTH preseason training camps in professional Australian-Football players. A secondary aim was to identify potential factors that may influence responsiveness to altitude exposure, such as preintervention $\mathrm{Hb}_{\text {mass }}$, energy balance and health status. It was hypothesised that there would be a moderately strong correlation between the magnitude of physiological changes from exposure 1 to exposure 2 .

\section{METHODS}

Subjects

Twelve Australian-Football players completed a 19-day (ALT1) and 18-day (ALT2) moderate altitude $(\sim 2100 \mathrm{~m})$ training camp, separated by 
12 months. Results from ALT1 have been previously reported. ${ }^{6}$ An additional 20 participants completed only one of the two training camps (ALT1-additional $\mathrm{n}=9$, ALT2-additional $\mathrm{n}=11$ ). All training and testing took place during the Australian Football League preseason from November to January, following a 6-week, off-season break. All participants provided written informed consent. All participants were supplemented with oral ferrous sulfate $(325 \mathrm{mg} /$ day $)$ throughout the intervention period, and athletes identified as having low serum ferritin preintervention (serum ferritin $\leq 30 \mu \mathrm{g} / \mathrm{L} ; \mathrm{n}=3$ ) were given a single, $2 \mathrm{~mL}$ ferrum $\mathrm{H}$ injection (Aspen Pharmacare, St Leonards, Australia; equivalent to $100 \mathrm{mg}$ of iron) prior to the altitude camp.

\section{Training}

During ALT1, participants completed an 8-week training block, including 19 days living and training at moderate altitude in Flagstaff, Arizona, USA (elevation $\sim 2100 \mathrm{~m}$ ). One year later, participants completed a similar 8-week training block, including 18 days living and training at moderate altitude in Park City, Utah, USA (elevation $\sim 2000 \mathrm{~m}$ ). Both training blocks included endurance training, resistance exercise and football specific training (see table 1). All training was prescribed by team coaches and monitored through session rating of perceived exertion (RPE). ${ }^{8}$ This method calculates a total load (arbitrary units (AU)) by multiplying the session-RPE (Borg's Category Ratio 10 -Scale) by the session duration, which is a valid method to quantify training loads in high-intensity, intermittent team sports. ${ }^{9}$

\section{Haematological measures}

All participants' Hbmass was measured using the optimised carbon monoxide $(\mathrm{CO})$ rebreathing technique ${ }^{10} 5$ days $\left(\mathrm{D}_{-5}\right)$ before altitude exposure (PRE see figure 1 ). $\mathrm{Hb}_{\text {mass }}$ was measured again one $\left(\mathrm{D}_{1}\right), 13\left(\mathrm{D}_{13}\right)$ and 17 days $\left(\mathrm{D}_{17} / \mathrm{POST}_{1}\right)$ after ascent during ALT2 only, and 5 days postdescent (POST 1 ) in ALT1 only. $\mathrm{Hb}_{\text {mass }}$ was measured again 28 days postdescent in both groups $\left(\mathrm{POST}_{2}\right)$. Change in $\mathrm{Hb}_{\text {mass }}\left(\Delta \mathrm{Hb}_{\text {mass }}\right)$ was calculated from PRE in ALT1, and from the mean of $D_{-5}$ and $D_{1}$ in ALT2. Briefly, participants rebreathed a bolus of $99 \%$ CO equivalent to $1.0 \mathrm{~mL} / \mathrm{kg}$ of body mass through a glass spirometer (BloodTec, Bayreuth, Germany) for $2 \mathrm{~min}$. Per cent carboxyhaemoglobin $(\% \mathrm{HbCO})$ in fingertip capillary blood was measured using the same OSM3 hemoximeter (Radiometer, Copenhagen, Denmark) before and $7 \mathrm{~min}$ after administration of the $\mathrm{CO}$ dose. $\mathrm{CO}$ doses administered at altitude were

Table 1 Typical training week during intervention period

\begin{tabular}{lllllll}
\hline Day & $\mathbf{1}$ & $\mathbf{2}$ & $\mathbf{3}$ & $\mathbf{4}$ & $\mathbf{5}$ & $\mathbf{6}$ \\
\hline AM & & Football & Technical & Football & Football & Resistance \\
PM & Cross train & Resistance & Resistance & Cross train & & Hike \\
Day & 7 & 8 & 9 & 10 & 11 & 12 \\
AM & Hike & Football & Resistance & & Football & \\
PM & & & Cross Train & & Resistance & Cross train \\
Day & 13 & 14 & 15 & 16 & 17 & 18 \\
AM & Football & Resistance & Football & Resistance & Resistance & Football \\
PM & Resistance & Technical & & Technical & Cross train & \\
\hline
\end{tabular}

Football=Australian-Football specific skills and running (90-120 min) resistance=strength training $(40-70 \mathrm{~min})$, cross train=non-specific training (eg, swimming, cycling and boxing; 20-60 min), technical=skills based Australian-Football session (light intensity; 20-60 $\mathrm{min}$ ), hike=outdoor recreational hiking (120-240 $\mathrm{min}$ ). adjusted for changes in the partial pressure (doses at $\sim 2000 \mathrm{~m}$ equivalent to $1.3 \mathrm{~mL} / \mathrm{kg}$ ). Six repeat measures of $\% \mathrm{HbCO}$ were made for improved precision in $\mathrm{Hb}_{\text {mass }}$ estimation. ${ }^{11} \mathrm{All} \mathrm{Hb}_{\text {mass }}$ measurements were performed by the same technician. Venous blood samples were collected at PRE, 3 days $\left(\mathrm{D}_{3}\right)$ and 16 days $\left(\mathrm{D}_{16}\right)$ after ascent and 13 days postdescent (POST $\left.\mathrm{D}_{\mathrm{D} 13}\right)$ in ALT2 only. Samples were centrifuged, serum decanted and frozen at $-80^{\circ} \mathrm{C}$, and transported to Canberra, Australia for analysis of serum EPO (for ALT2 only), in one batch, using an automated solid-phase, sequential chemiluminescent Immulite assay (Diagnostics Product Corporation, Los Angeles, USA). PRE and POST $_{\mathrm{D} 13}$ samples were analysed for reticulocyte count using a Sysmex XE-5000 Automated Haematology Analyser (Roche Diagnostics, Castle Hill, Australia) at St Vincent's Hospital Pathology (Fitzroy, Australia), while $\mathrm{D}_{3}$ and $\mathrm{D}_{16}$ samples were analysed using a Sysmex XT-4000i Automated Haematology Analyser (Sysmex, Lincolnshire, USA) at Park City Medical Centre (Park City, USA). Serum ferritin was assessed at PRE using an AU5800 immuno-turbidimetric assay (Beckman Coulter, Lane Cove, Australia) to identify iron-deficient participants.

\section{Body mass and illness}

Body mass was monitored daily on waking (07:00-08:00) in a well hydrated state (confirmed through urine specific gravity measures (URC- $\mathrm{N}_{\mathrm{E}}$, Atago, Tokyo, Japan)) throughout the intervention period using electronic scales (Tanita, Kewdale, Australia). Changes in body mass were calculated from the first to the last day at altitude during both camps. Athletes were classified as 'ill' if any training session was missed throughout the intervention period due to physical illness, excluding musculoskeletal injuries.

\section{Statistical analysis}

A magnitude-based statistical approach ${ }^{12}$ was used to detect small effects of practical importance. Data were log-transformed to account for non-uniformity error. Differences within and between groups were assessed with dependent and independent $t$ tests for unequal variance. ${ }^{12}$ The magnitude of changes were assessed in relation to the smallest worthwhile change (SWC), set to $2 \%$ for $\mathrm{Hb}_{\text {mass }}$ and a small effect size $(\mathrm{d}=0.2 \times$ the between-participant SD for PRE) for other variables. Observed effects were reported as the mean change or difference $\pm 90 \%$ confidence limits. Effects were termed positive, trivial or negative depending on the magnitude of the change relative to the SWC and assigned a qualitative descriptor according to the likelihood of the change exceeding the SWC: $50-74 \%$ 'possible', 75-94\% 'likely', 95-99\% 'very likely', >99\% 'almost certainly'. ${ }^{13}$ Effects where the $90 \%$ CI overlapped simultaneously the substantially positive and negative thresholds were deemed 'unclear'. The magnitude of individual responses were calculated from the square root of the difference in the variance of the change scores. ${ }^{14}$ A Pearson's correlation coefficient was used to examine the relationship between percentage change in $\mathrm{Hb}_{\text {mass }}\left(\% \Delta \mathrm{Hb}_{\text {mass }}\right)$ from ALT1 to ALT2 and the relationship between initial $\mathrm{Hb}_{\text {mass }}$ and change in $\mathrm{Hb}_{\text {mass. }}$. Because one participant's results appeared to heavily influence the relationship from year to year, a Pearson's correlation was also performed after removing these data. Participants who reported illness (ALT1 $n=2$, ALT2 $n=3$, total $n=5$ ) were removed from correlation analyses, as proinflammatory cytokines suppress EPO production. ${ }^{15}$ Participants were also retrospectively divided into

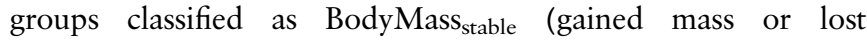

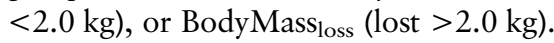




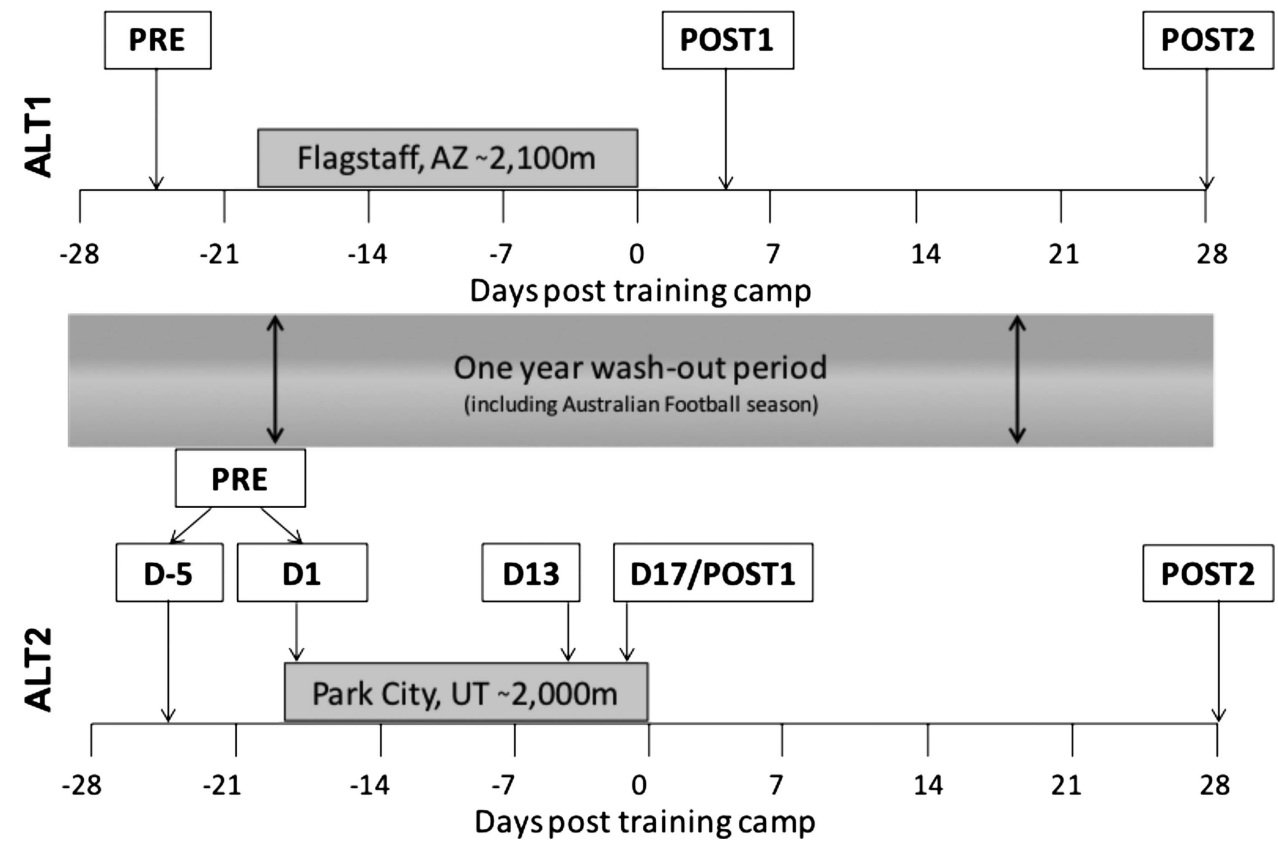

Figure 1 Timeline of haemoglobin mass $\left(\mathrm{Hb}_{\text {mass }}\right)$ collection over ALT1 and ALT2.

\section{RESULTS}

Training load, duration and RPE

Weekly training load, duration and RPE for all participants are presented in table $2 \mathrm{~A}$. The overall training load was very likely 5.5 $\pm 4.8 \%$ (mean $\pm 90 \% \mathrm{CI}$ ) higher and mean RPE almost certainly $7.2 \pm 2.6 \%$ higher in ALT1 compared to ALT2. Training duration was very likely $12.6 \pm 3.6 \%$ higher in ALT2 compared to ALT1.

The weekly training load, duration and RPE for healthy repeat participants $(n=9)$ are presented in table 3 . There was an unclear $0.5 \pm 3.5 \%$ difference in the overall training load between ALT1 and ALT2. The overall mean RPE was very likely $5.1 \pm 2.8 \%$ lower and training duration was almost certainly $13.5 \pm 2.4 \%$ higher in ALT2 compared to ALT1.

\section{Haemoglobin mass}

$H b_{\text {mass }}$ (all participants): The typical error of $\mathrm{Hb}_{\text {mass }}$ for the pooled data of all 32 participants, for measures made approximately 5 days apart, was $2.6 \%$ (90\% CI of $2.1 \%$ to $3.3 \%)$. Mean $\left( \pm\right.$ SD) Hb $b_{\text {mass }}$ in ALT1 $(n=21)$ and ALT2 $(n=23)$ groups preintervention was $992 \pm 129$ and $1008 \pm 159 \mathrm{~g}$, respectively. $\% \Delta \mathrm{Hb}_{\text {mass }}$ from baseline is displayed in figure 2 . Mean $\%$ $\Delta \mathrm{Hb}_{\text {mass }}( \pm 90 \% \mathrm{CL})$ was very likely increased at $\mathrm{POST}_{1}$ in ALT1 (3.6 $\pm 1.6 \%$, with individual responsiveness of $1.3 \%$ ) and almost certainly increased at $\mathrm{D}_{13}(3.9 \pm 1.0 \%)$ and $\mathrm{D}_{17}(4.0$ $\pm 1.3 \%$, with individual responsiveness of $2.2 \%$ ) in ALT2. Differences in $\% \Delta \mathrm{Hb}_{\text {mass }}$ between ALT1 and ALT2 from PRE to postintervention (POST 1 and $\mathrm{D}_{17}$ during ALT1 and ALT2, respectively) were unclear $(-1.3 \pm 7.0 \%)$. $\mathrm{Hb}_{\text {mass }}$ returned to baseline at 4 weeks postaltitude in ALT1 and ALT2. There was a negative correlation $(\mathrm{R}=-0.51, \mathrm{p}=0.04$; see figure 3 ) between initial $\mathrm{Hb}_{\text {mass }}$ relative to body mass $\left(\mathrm{RelHb} \mathrm{b}_{\text {mass }}\right.$ ) and $\% \Delta \mathrm{Hb}$ mass

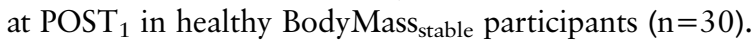

$H b_{\text {mass }}$ (participants completing ALT1 and ALT2): There was a trivial difference in $\mathrm{Hb}_{\text {mass }}$ at PRE for ALT1 $(1023 \pm 143 \mathrm{~g})$

Table 2 Training load, training duration and rate of perceived exertion (mean \pm SD) during ALT1 and ALT2

\begin{tabular}{|c|c|c|c|}
\hline & ALT1 $(n=21)$ & ALT2 $(n=23)$ & $\begin{array}{l}\text { Per cent chances for ALT1 to be } \\
\text { greater/similar/smaller than the SWC compared with ALT2 }\end{array}$ \\
\hline \multicolumn{4}{|c|}{ Training load (arbitrary units) } \\
\hline Preintervention week & $2260 \pm 571$ & $2668 \pm 488$ & 2/14/84 (ALT2 very likely higher) \\
\hline Week 1 & $4765 \pm 685$ & $4861 \pm 695$ & 42/43/15 (Unclear difference) \\
\hline Week 2 & $4962 \pm 313$ & $4790 \pm 538$ & 74/24/3 (ALT1 possibly higher) \\
\hline Week 3 & $4536 \pm 240$ & $3714 \pm 194$ & 100/0/0 (ALT1 almost certainly higher) \\
\hline \multicolumn{4}{|l|}{ Training duration (min) } \\
\hline Preintervention week & $536 \pm 118$ & $705 \pm 128$ & 0/0/100 (ALT2 almost certainly higher) \\
\hline Week 1 & $702 \pm 95$ & $885 \pm 59$ & 0/0/100 (ALT2 almost certainly higher) \\
\hline Week 2 & $748 \pm 41$ & $697 \pm 37$ & 0/0/100 (ALT1 almost certainly higher) \\
\hline Week 3 & $597 \pm 9$ & $620 \pm 12$ & 0/0/100 (ALT2 almost certainly higher) \\
\hline \multicolumn{4}{|l|}{ Rate of perceived exertion } \\
\hline Preintervention week & $4.84 \pm 0.58$ & $5.37 \pm 0.51$ & 0/0/100 (ALT2 almost certainly higher) \\
\hline Week 1 & $6.97 \pm 0.26$ & $5.48 \pm 0.58$ & 100/0/0 (ALT1 almost certainly higher) \\
\hline Week 2 & $6.35 \pm 0.13$ & $6.12 \pm 0.49$ & 92/7/1 (ALT1 very likely higher) \\
\hline Week 3 & $6.49 \pm 0.38$ & $5.94 \pm 0.28$ & 100/0/0 (ALT1 almost certainly higher) \\
\hline
\end{tabular}


Table 3 Training load, training duration and rate of perceived exertion (mean \pm SD) for the nine participants completing both ALT1 and ALT2

\begin{tabular}{llll}
\hline & ALT1 & ALT2 & $\begin{array}{l}\text { Per cent chances for ALT1 to be greater/similar/smaller } \\
\text { than the SWC compared with ALT2 }\end{array}$ \\
\hline $\begin{array}{l}\text { Training load (arbitrary units) } \\
\text { Preintervention week }\end{array}$ & & \\
$\quad \begin{array}{l}\text { Week 1 } \\
\text { Week 2 }\end{array}$ & $2497 \pm 349$ & $2838 \pm 201$ & $1 / 2 / 97$ (ALT2 very likely higher) \\
Week 3 & $5138 \pm 150$ & $5091 \pm 323$ & $49 / 31 / 20$ (Unclear difference) \\
Training duration (min) & $5002 \pm 116$ & $4929 \pm 337$ & $45 / 47 / 8$ (Unclear difference) \\
Preintervention week & $3833 \pm 257$ & $3711 \pm 185$ & $75 / 18 / 7$ (ALT2 possibly higher) \\
Week 1 & & & \\
Week 2 & $550 \pm 93$ & $765 \pm 80$ & $0 / 0 / 100$ (ALT2 almost certainly higher) \\
Week 3 & $730 \pm 15$ & $902 \pm 10$ & $0 / 0 / 100$ (ALT2 almost certainly higher) \\
Rate of perceived exertion & $763 \pm 8$ & $696 \pm 39$ & $0 / 0 / 100$ (ALT1 almost certainly higher) \\
Preintervention week & $625 \pm 13$ & $597 \pm 21$ & $0 / 0 / 100$ (ALT1 almost certainly higher) \\
Week 1 & & & $100 / 0 / 0$ (ALT2 almost certainly higher) \\
Week 2 & $4.71 \pm 0.57$ & $5.56 \pm 0.28$ & $99 / 1 / 0$ (ALT1 very likely higher) \\
Week 3 & $6.17 \pm 0.19$ & $5.74 \pm 0.38$ & $85 / 11 / 3$ (ALT1 very likely higher) \\
\hline
\end{tabular}

versus ALT2 $(1017 \pm 135 \mathrm{~g})$ in participants completing both training camps $(\mathrm{n}=12)$. In these participants, $\mathrm{Hb}_{\text {mass }}$ very likely increased at $\mathrm{POST}_{1}$ in ALT1 (3.7 $\left.\pm 2.5 \%\right)$ and at $\mathrm{D}_{17}$ in ALT2 $(4.2 \pm 2.4 \%)$. A weak correlation between individual $\% \Delta \mathrm{Hb}_{\text {mass }}$ was observed between ALT1 and ALT2 $(n=12 ; R=0.12$, $\mathrm{p}=0.71$ ), which was marginally stronger when participants who reported illness in ALT2 were not included $(n=9 ; \mathrm{R}=0.21$, $\mathrm{p}=0.59$ ) see figure 4). After removing one participant who was influencing the results heavily, the correlation between $\mathrm{Hb}_{\text {mass }}$ from year to year reduced to $\mathrm{R}=0.02(\mathrm{n}=8, \mathrm{p}=0.96$, figure 4).

$\mathrm{Hb} b_{\text {mass }}$ (ill vs healthy participants): figure 5A shows \% $\Delta \mathrm{Hb}_{\text {mass }}$ for participants separated into healthy $(\mathrm{n}=39)$ and ill $(n=5)$ groups. Ill participants had a trivial $0.2 \pm 2.4 \%$ change in $\mathrm{Hb}_{\text {mass }}$ at POST $\mathrm{P}_{1}$, which was almost certainly $3.9 \pm 1.1 \%$ lower than changes in healthy participants. There was a trivial 1.1 $\pm 1.6 \%$ difference in $\mathrm{Hb}_{\text {mass }}$ between ill and healthy participants at $\mathrm{POST}_{2}$.

$H b_{\text {mass }}$ (BodyMass stable $_{\text {vs BodyMass }}$ loss participants): Changes in body mass and $\mathrm{Hb}_{\text {mass }}$ and body mass for the BodyMass stable $(\mathrm{n}=30)$ and BodyMass $\mathrm{loss}_{(\mathrm{n}}(\mathrm{n})$ groups are presented in figure $5 \mathrm{~B}, \mathrm{C}$, respectively. BodyMass ${ }_{\text {loss }}$ participants very likely lost 2.6

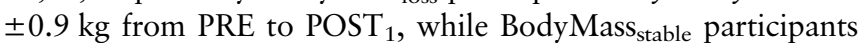
had a trivial $0.2 \pm 1.3 \mathrm{~kg}$ change in body mass. BodyMass ${ }_{\text {loss }}$ participants possibly increased in $\mathrm{Hb}_{\text {mass }}$ by $2.6 \pm 1.8 \%$ at POST $_{1}$, which was possibly 2.4 $2.1 \%$ lower than the changes in the BodyMass stable group. At $\mathrm{POST}_{2}$, BodyMass pants had a possible $2.3 \pm 2.7 \%$ decrease in $\mathrm{Hb}_{\text {mass }}$ from PRE, which was very likely $3.9 \pm 1.9 \%$ lower than the BodyMass stable $_{\text {e }}$ group.

\section{Reticulocytes and EPO-for ALT2 only}

Figure 6 shows reticulocyte percentage and EPO concentrations for ALT2. Compared with PRE, reticulocytes almost certainly increased by $39 \pm 12 \%$ at $\mathrm{D}_{3}$ and very likely increased $16 \pm 10 \%$ at D16. Reticulocytes almost certainly reduced from PRE by $27 \pm 10 \%$ at POST $_{\mathrm{D} 13}$. EPO almost certainly increased by $36 \pm 10 \%$ and $22 \pm 10 \%$ from $P R E$ at $D_{3}$ and $D_{16}$, respectively, and almost certainly reduced from PRE by $16 \pm 16 \%$ at $\operatorname{POST}_{\mathrm{D} 13}$.

\section{DISCUSSION}

The main finding of the current investigation is that, while two preseason moderate altitude camps yield a similar group mean increase $(\sim 4 \%)$ in $\mathrm{Hb}_{\text {mass }}$ of elite footballers, there is wide variability in this erythropoietic response and individual athletes do not exhibit consistency in changes in $\mathrm{Hb}_{\text {mass }}$ from year to year.
Figure 2 Percentage changes in haemoglobin mass $\left(\mathrm{Hb}_{\text {mass }}\right)$ (mean $\pm 90 \% \mathrm{Cl}$ ) after altitude ALT1 and ALT2.

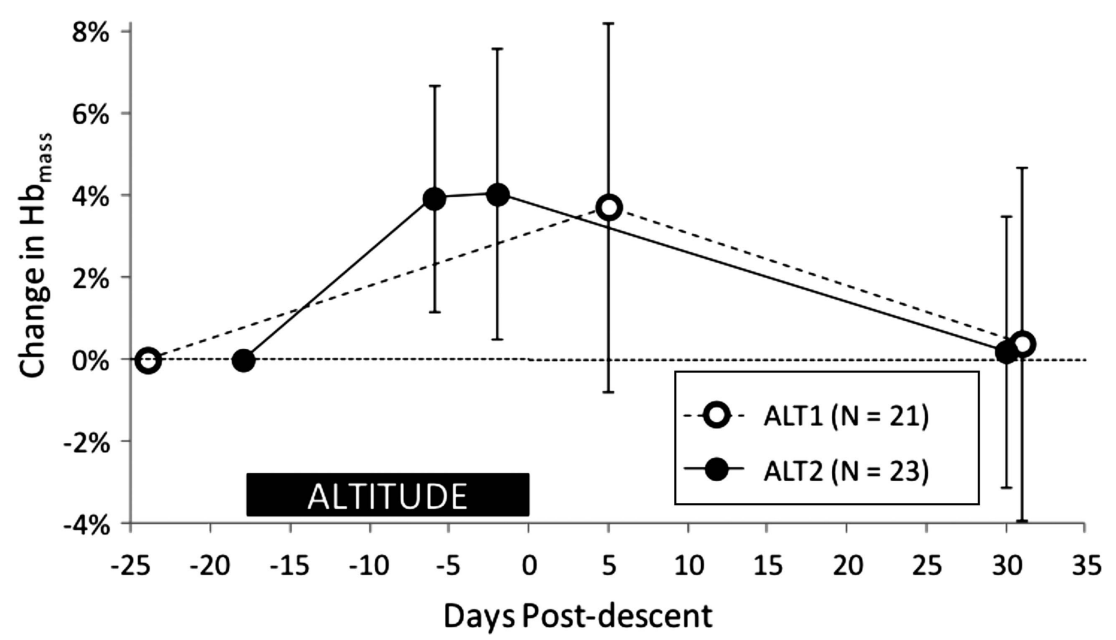




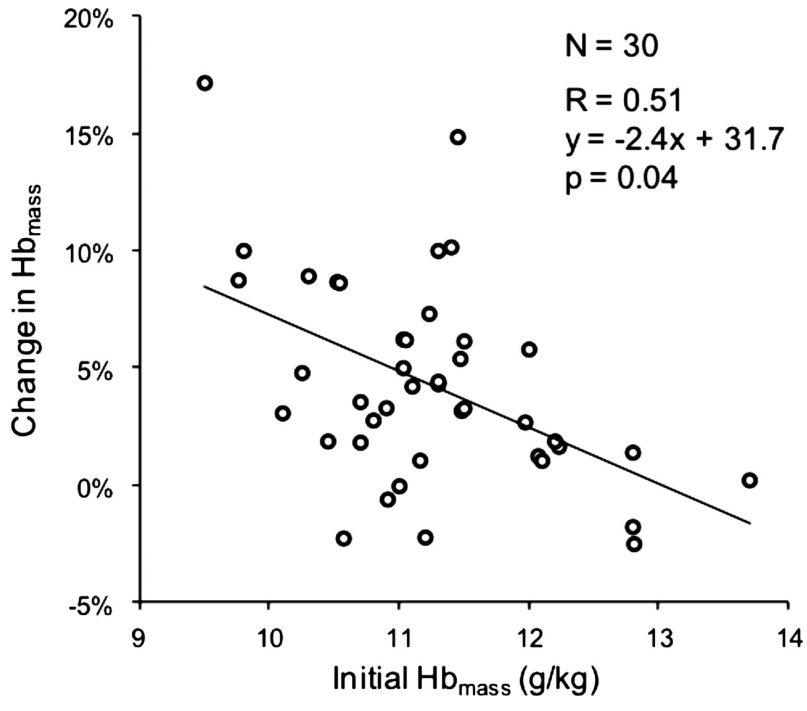

Figure 3 Change in haemoglobin mass $\left(\mathrm{Hb}_{\text {mass }}\right)$ versus initial $\mathrm{Re} \mathrm{Hb}_{\text {mass }}$ in healthy and BodyMass stable participants pooled for ALT1 and ALT2 altitude camps.

Thus, a 'responder' or 'non-responder' to altitude does not appear to be a fixed trait with respect to changes in $\mathrm{Hb}_{\text {mass }}$. Some of the variability in erythropoietic response may be explained by the incidence of illness, reductions in body mass and precamp $\mathrm{Hb}_{\text {mass, }}$, but large variability is still evident in healthy athletes who maintain body mass. Another important finding is that almost all of the erythropoietic response of an 18-day altitude camp (ALT2) occurred within the first 13 days of exposure.

Repeatability of changes in $\mathrm{Hb}_{\text {mass }}$

We previously reported that elite team-sport athletes achieved a mean increase of $\sim 3.6 \%$ in $\mathrm{Hb}_{\text {mass }}$ over a 19-day altitude camp. ${ }^{6}$ During a subsequent 18-day exposure (ALT2), our

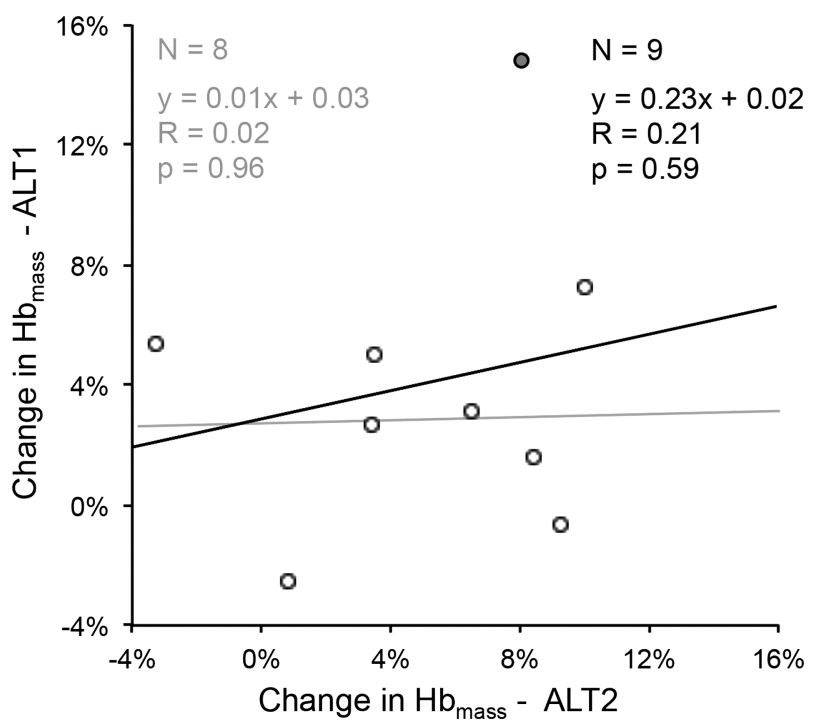

Figure 4 Change in haemoglobin mass $\left(\mathrm{Hb}_{\text {mass }}\right)$ during ALT1 versus change in $\mathrm{Hb}_{\text {mass }}$ during ALT2. Three participants were removed from this analysis due to illness throughout the study period $(n=9)$. Grey filled circle represents an outlier; regression line and associated equations when the outlier is removed are shown in grey. participants achieved a similar mean increase in $\mathrm{Hb}_{\text {mass }}$ of $4 \%$. However, in agreement with other work, ${ }^{14} 16$ there was considerable individual variability in the erythropoietic response. Chapman et $a l^{4}$ introduced the concept of 'responders' and 'non-responders' to altitude when they found that participants who achieved the greatest improvements in $5000 \mathrm{~m}$ running performance following LHTL also demonstrated the greatest erythropoietic response. This led to suggestions that the magnitude of an individual's response to altitude may be influenced by genetically determined traits. ${ }^{4}{ }^{17}$ This theory proposes that individuals should respond similarly on subsequent hypoxic exposures, given the same hypoxic dose (ie, exposure time and degree of hypoxia). However, we observed a small correlation between changes in $\mathrm{Hb}_{\text {mass }}$ following ALT1 and ALT2 $(\mathrm{R}=0.21)$ in participants who completed both training camps $(n=9)$, which was reduced to $\mathrm{R}=0.02$ when the sole outlier was removed. This supports previous investigations ${ }^{3} 5$ that have reported weak ( $\mathrm{R} \sim 0.10-0.38)$ relationships between changes in $\mathrm{Hb}_{\text {mass }}$ following repeated altitude exposures $\sim 1-3$ months apart, suggesting that responsiveness to a given hypoxic stimulus is not a fixed trait. The $\sim 2 \%$ typical error of the optimised CO rebreathing technique ${ }^{10} 18$ along with natural biological variations ${ }^{19} 20$ may, in part, contribute to the variability from exposure to exposure.

\section{Timeline of erythropoietic response}

It is well accepted that a sufficient hypoxic dose (h/day; number of days; degree of hypoxia) is required to induce detectable erythropoietic benefit. ${ }^{21} 22$ Wilber et $a l^{21}$ suggested that altitude training at 2000-2500 $\mathrm{m}$ for at least $22 \mathrm{~h}$ /day and a minimum of 4 weeks is required to optimise physiological benefits. However, these recommendations are based on data from studies that examined erythrocyte volumes pre and postaltitude exposure, with little data addressing the time course of responses. Recently, detectable increases in $\mathrm{Hb}_{\text {mass }}$ have been reported with exposures as short as $11^{23}$ and 13 days ${ }^{5}$. Similarly, we observed an $\sim 4 \%$ increase in $\mathrm{Hb}_{\text {mass }}$ after 13 days at altitude, with no additional increases by day 17 . This suggests that erythropoietic benefits are possible with shorter duration altitude training camps than commonly recommended, given sufficient altitude/hypoxia. ${ }^{21}$ A 2 -week time course may have significant implications for team-sport organisations, which often schedule altitude camps during limited preseason periods and may face financial restrictions during longer duration camps due to travel/accommodation costs for athletes and support staff.

\section{Effect of initial RelHb $b_{\text {mass }}$}

We found a similar relationship between initial $\mathrm{RelHb}_{\text {mass }}$ and $\% \Delta \mathrm{Hb}_{\text {mass }}$ as in our original investigation. ${ }^{6}$ These data support the work of Robach and Lundby, ${ }^{7}$ which suggests that athletes starting with low RelHb $b_{\text {mass }}$ have the ability to increase $\mathrm{Hb}_{\text {mass }}$ to a greater extent following hypoxic interventions. Others have proposed that athletes with initially high $\operatorname{RelHb}_{\text {mass }}(\sim 14.7 \mathrm{~g} / \mathrm{kg})$ may have already 'maximised' this component of their physiological capacity through training at sea level, ${ }^{24}$ with limited opportunity to further increase $\mathrm{Hb}_{\text {mass }}$ through altitude interventions. However, subsequent research from the same group showed that increases in $\mathrm{Hb}_{\text {mass }}$ can be achieved in cyclists possessing elevated initial RelHb $\mathrm{b}_{\text {mass }}(\sim 14.2 \mathrm{~g} / \mathrm{kg}) .^{23}$ It is also possible that altitude training interventions may increase $\mathrm{Hb}_{\text {mass }}$ to a given individual's physiological limit, and responsiveness may therefore vary depending on an individual's baseline $\mathrm{Hb}_{\text {mass. }}{ }_{5}$ Collectively, these data ${ }^{5-7}$ suggest that team-sport athletes with a 
Figure 5 Change in haemoglobin mass $\left(\mathrm{Hb}_{\text {mass }}\right)$ in ill and healthy participants (A), as well as change in mass (B) and change in $\mathrm{Hb}_{\text {mass }}$ (C) in BodyMass $_{\text {stable }}$ and BodyMass loss $_{\text {ons }}$ groups.

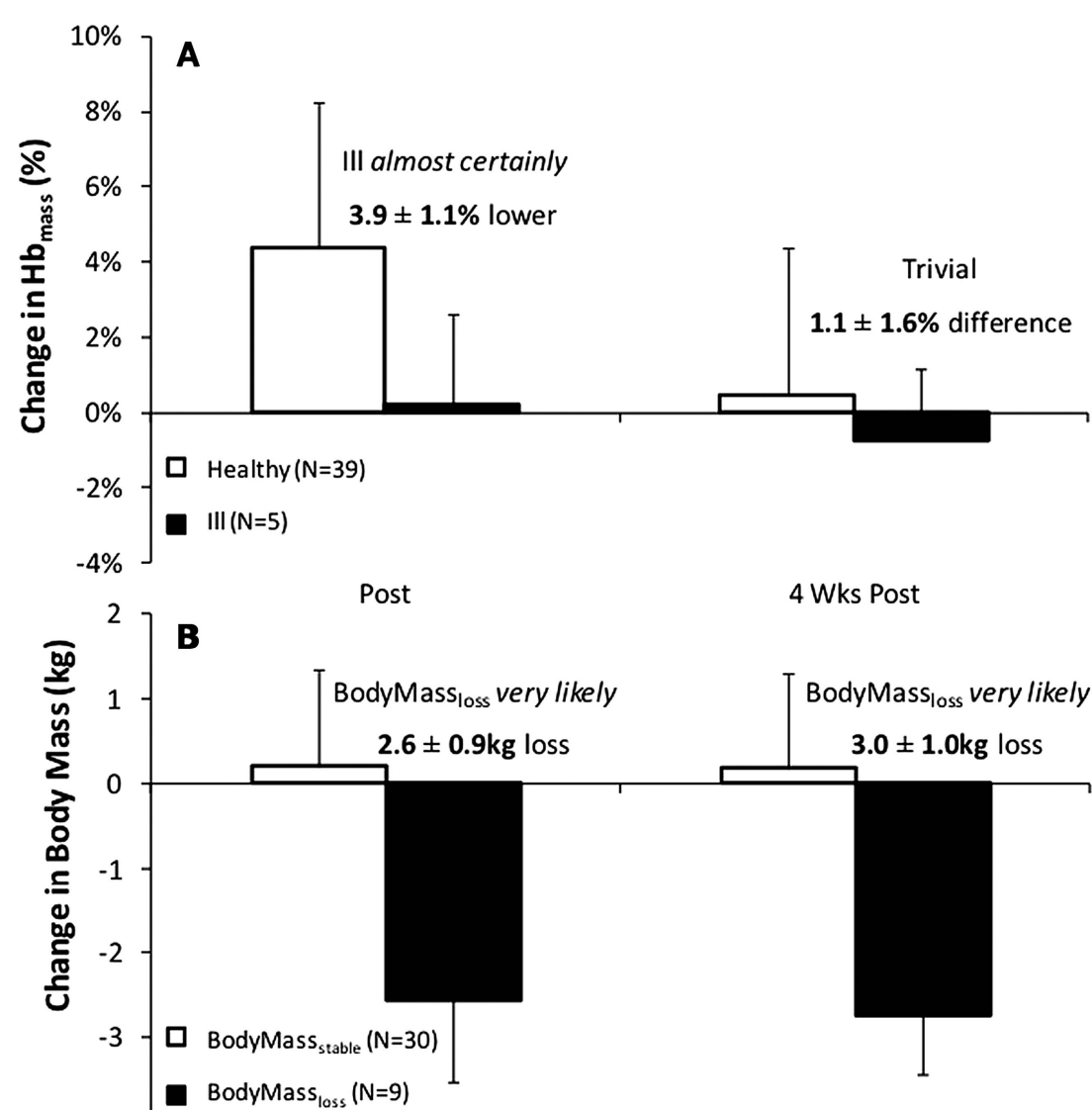

4 Wks Post

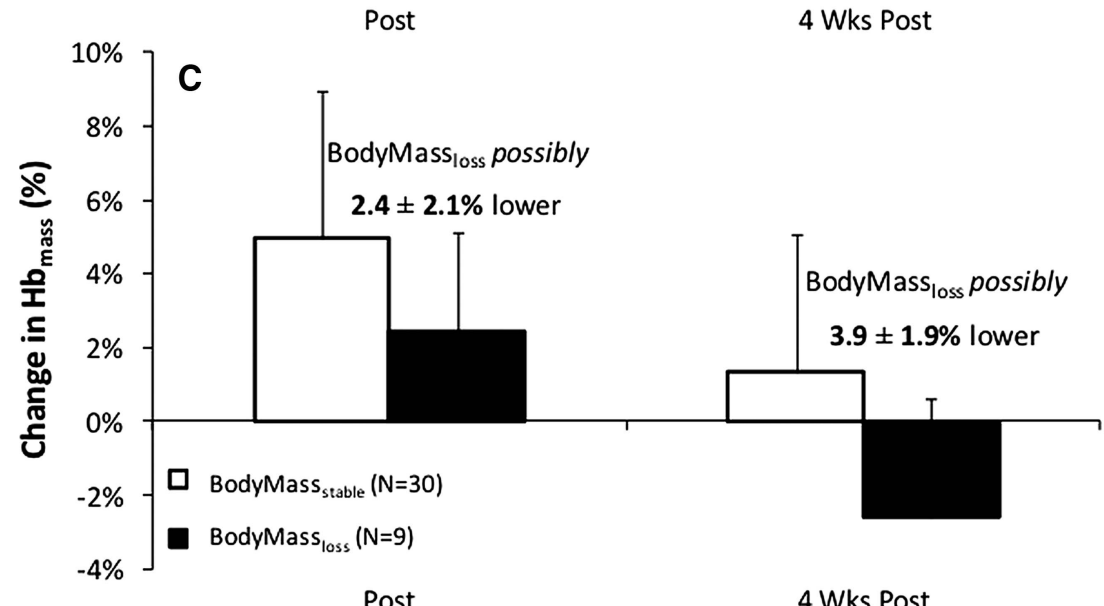

Post

4 Wks Post

higher initial RelHb $\mathrm{b}_{\text {mass }}$ may have an attenuated ability to increase $\mathrm{Hb}_{\text {mass }}$ with altitude training interventions.

\section{Effect of illness on erythropoiesis}

It has been suggested that athletes suffering from infection/ illness/injury that results in increased inflammation may have limited erythropoietic responses to altitude exposures. ${ }^{5} 6$ Indeed, Wachsmuth et $a l^{5}$ reported attenuated changes in $\mathrm{Hb}_{\text {mass }}$ in sick/injured athletes following LHTH interventions at $2320 \mathrm{~m}$. Similarly, we observed an attenuated erythropoietic response in participants experiencing illness during ALT1 $(n=2)$ and ALT2 $(n=3)$ (see figure 5A). Proinflammatory cytokines, such as interleukin 1(IL-1), are known to suppress the release of EPO, ${ }^{15}$ and EPO data for ill participants during ALT2 are highlighted in figure 6B. Participants (b) and (c) (in figure 6B) suffered illness immediately preceding the camp, which was accompanied by low EPO levels before and throughout the camp duration. Participant (a) fell ill on arriving at a high altitude and displayed suppressed EPO responses thereafter. Making statistical inferences are difficult, given that instances of illness/injury are low in our investigation $(n=5)$ and in Wachsmuth et $a l^{5} \quad(\mathrm{n}=7)$. However, these data support the hypothesis that illness/injury may limit the erythropoietic benefits associated with prolonged hypoxic exposures.

\section{Effect of body mass reductions on erythropoiesis}

Participants experiencing reductions in body mass $(>2 \mathrm{~kg})$ achieved approximately half of the erythropoietic benefit as those maintaining body mass ( $2.5 \%$ vs $\sim 5 \%$ increase in $\mathrm{Hb}_{\text {mass }}$, respectively). Furthermore, at 4 weeks postaltitude, BodyMass ${ }_{\text {loss }}$ participants displayed $\mathrm{Hb}_{\text {mass }} \sim 2.3 \%$ below prealtitude levels. Our results are in contrast with those of Gough et al, ${ }^{25}$ who modelled that body mass changes over approximately 6 months did not significantly alter $\mathrm{Hb}_{\text {mass }}$; for instance, that a $10 \%$ loss of 
Figure 6 Reticulocyte (A) and erythropoietin (EPO) (B) response during ALT2. Black circles and error bars show group change as mean \pm SD and grey circles show individual responses. Dark grey broken lines depict responses of three participants during (a) altitude exposure. NB. EPO data at PRE missing for participant (b) due to being absent from testing as a who reported illness before $(b+c)$ and result of illness.
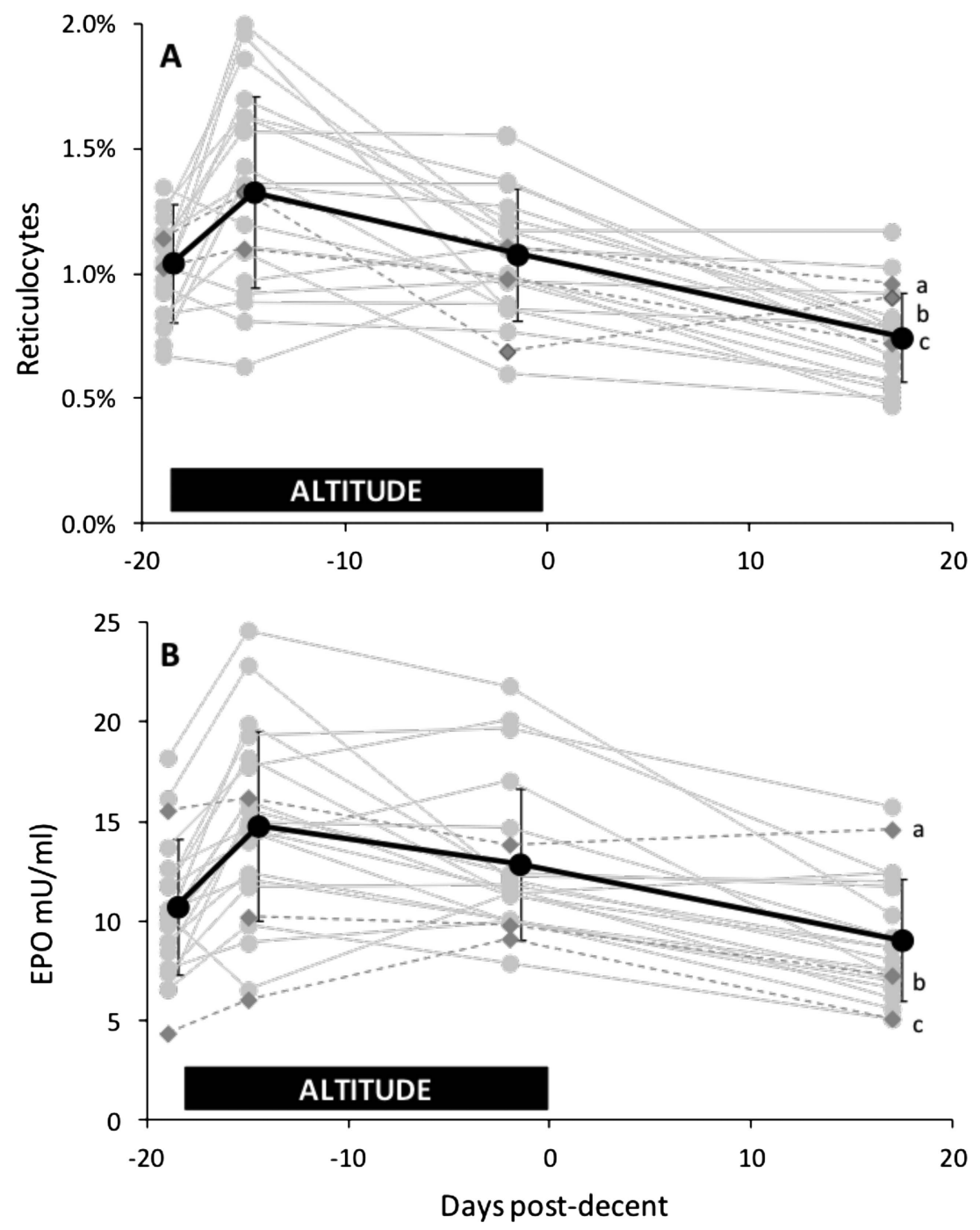

body mass would only decrease $\mathrm{Hb}_{\text {mass }}$ by $1.4 \%$. In contrast, the $2.6 \mathrm{~kg}$ reduction in body mass within the Australian-Footballer subgroup over 18-19 days suggests a mismatch between energy consumption and energy expenditure and thus an overall catabolic state, which may not support an anabolic process like erythropoiesis. Evidence in maintenance haemodialysis patients with haemodialysis suggests that poor appetite and low protein intake are associated with increased serum concentrations of inflammatory markers (including C reactive protein, IL-6 and tumour necrosis factor- $\alpha$ ) and increased synthetic EPO dose requirements. $^{26}$ While mechanisms for a poor erythropoietic

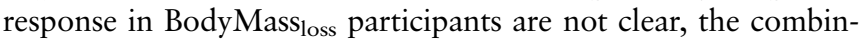
ation of altitude exposure and weight loss appears to be counterproductive for $\mathrm{Hb}_{\text {mass }}$ maintenance.

\section{Limitations}

This research was conducted with a relatively small sample of elite Australian-Football players. Even when using a magnitudebased statistical approach, ${ }^{12}$ the small sample size limitations are most apparent in our attempts to quantify the effects of initial $\mathrm{Hb}_{\text {mass}}$, as well as loss of body mass and of illness on the response to altitude. A further limitation is the use of two different Sysmex haematology analysers for the reticulocyte measures, since even Sysmex analysers that are calibrated within the manufacturer's tolerances can have biases of the order of $0.3-0.5 \%$ reticulocytes. ${ }^{27}$ The applied nature of this research also led to a number of limitations, which should be considered when interpreting our results. ALT1 and ALT2 were conducted in different locations over different durations (19 and 18 days, respectively). However, the altitude at these locations is very similar $(\sim 2100 \mathrm{~m})$ and the overall hypoxic dose between camps differed by only $18 \mathrm{~h}$. The temporal measurements of $\mathrm{Hb}_{\text {mass }}$ differed between ALT1 and ALT2; POST 1 was taken 5 days postaltitude (ALT1) compared with the penultimate day at altitude (ALT2). Therefore, the potential confounding effects of neocytolysis upon return to sea level ${ }^{23} 28$ during ALT1 may account for some of the variability between the two exposures.

\section{CONCLUSION}

This investigation was conducted in an ecologically valid environment, with professional team-sport athletes engaging in preseason altitude training in an attempt to improve subsequent performance at sea level. As responsiveness to a given altitude exposure does not appear to be a fixed trait, it is not currently possible for individual athletes to be identified as 'responders' or 'non-responders' following a single altitude exposure. To optimise the erythropoietic benefit from an LHTH intervention, athletes should be well prepared, in good health and maintain body mass throughout its duration. Healthy team-sport athletes should expect a $3-4 \%$ increase in $\mathrm{Hb}_{\text {mass }}$ following an 18-19 day altitude training camp, with this erythropoietic response possibly achievable in as short as 13 days. 


\section{What are the new findings}

- Team sport athletes produce repeatable group mean increases in $\mathrm{Hb}_{\text {mass }}(\sim 4 \%)$ over 18-19 day moderate altitude camps, and these benefits may be achieved in as short as 13 days.

- Individual athletes do not exhibit consistency in altitude-induced changes in $\mathrm{Hb}_{\text {mass }}$ from year to year, and thus a 'responder' or 'non-responder' to altitude does not appear to be a fixed trait.

- To achieve full erythropoietic benefit from altitude exposure, athletes should maintain body mass and remain free from illness immediately before and throughout the exposure.

\section{How might it impact on clinical practice in the near} future?

- Athletes may gain physiological benefits from participating in shorter duration ( $\sim 13$ days) altitude training camps than previously recommended.

- Strategies to maintain body mass and optimal health immediately before and throughout altitude training camps should be adopted.

Acknowledgements The authors would like to acknowledge the generous participation of all athletes in this research study. The authors acknowledge the contribution of Collingwood Football Club and their staff involved in making this project run smoothly. Special thanks are extended to Dr Doug Whyte and Professor Geraldine Naughton for their assistance with this project.

Contributors BM and DB were involved in the concept and design of the study, conducted the data collection and analysis and prepared the manuscript. CG and JK were involved in the concept and design of the study, data analysis and interpretation and preparation of the manuscript. KW assisted with data collection and analysis and manuscript preparation.

\section{Competing interests None.}

Ethics approval Australian Catholic University Human Research Ethics Committee. Provenance and peer review Not commissioned; externally peer reviewed.

Open Access This is an Open Access article distributed in accordance with the Creative Commons Attribution Non Commercial (CC BY-NC 3.0) license, which permits others to distribute, remix, adapt, build upon this work non-commercially, and license their derivative works on different terms, provided the original work is properly cited and the use is non-commercial. See: http://creativecommons.org/ licenses/by-nc/3.0/

\section{REFERENCES}

1 Friedmann B, Frese F, Menold E, et al. Individual variation in the erythropoietic response to altitude training in elite junior swimmers. Br J Sports Med 2005;39:148-53.

2 Stray-Gundersen J, Chapman RF, Levine BD. 'Living high-training low' altitude training improves sea level performance in male and female elite runners. J App/ Physiol 2001;91:1113-20.
3 Robertson EY, Saunders PU, Pyne DB, et al. Reproducibility of performance changes to simulated live high/train low altitude. Med Sci Sports Exerc 2010;42:394-401.

4 Chapman RF, Stray-Gundersen J, Levine BD. Individual variation in response to altitude training. J Appl Physiol 1998;85:1448-56.

5 Wachsmuth NB, Volzke C, Prommer N, et al. The effects of classic altitude training on hemoglobin mass in swimmers. Eur J Appl Physiol 2013;113:1199-211.

6 McLean BD, Buttifant D, Gore CJ, et al. Physiological and performance responses to a pre-season altitude training camp in elite team sport athletes. Int I Sports Physiol Perform 2013;8:391-9.

7 Robach $\mathrm{P}$, Lundby C. Is live high - train low altitude training relevant for elite athletes with already high total hemoglobin mass? Scand J Med Sci Sports 2012;22:303-5.

8 Foster C, Florhaug JA, Franklin J, et al. A new approach to monitoring exercise training. J Strength Cond Res 2001;15:109-15.

9 Scott TJ, Black CR, Quinn J, et al. Validity and reliability of the session-RPE method for quantifying training in Australian Football: a comparison of the CR10 and CR100 scales. J Strength Cond Res 2013;27:270-6.

10 Schmidt W, Prommer N. The optimised CO-rebreathing method: a new tool to determine total haemoglobin mass routinely. Eur J Appl Physiol 2005;95:486-95.

11 Alexander AC, Garvican LA, Burge CM, et al. Standardising analysis of carbon monoxide rebreathing for application in anti-doping. I Sci Med Sport 2011;14:100-5.

12 Hopkins WG, Marshall SW, Batterham AM, et al. Progressive statistics for studies in sports medicine and exercise science. Med Sci Sports Exerc 2009;41:3-13.

13 Batterham AM, Hopkins WG. Making meaningful inferences about magnitudes. Int J Sports Physiol Perform 2006;1:50-7.

14 Hopkins WG. A spreadsheet for analysis of straightforward controlled trials. Secondary A spreadsheet for analysis of straightforward controlled trials. 2003. http://www.sportsci.org/jour/03/wghtrials.htm

15 Jelkmann W. Proinflammatory cytokines lowering erythropoietin production. J Interferon Cytokine Res 1998;18:555-9.

16 Scoggin C, Doekel R, Kryger M, et al. Familial aspects of decreased hypoxic drive in endurance athletes. J App/ Physiol 1978;44:464-8.

17 Ge R-L, Witkowski S, Zhang Y, et al. Determinants of erythropoietin release in response to short-term hypobaric hypoxia. J Appl Physiol 2002;92:2361-7.

18 Garvican LA, Saunders PU, Pyne DB, et al. Hemoglobin mass response to simulated hypoxia 'blinded' by noisy measurement?. J Appl Physiol 2012;112:1797-8.

19 Garvican LA, Martin DT, McDonald W, et al. Seasonal variation of haemoglobin mass in internationally competitive female road cyclists. Eur J App/ Physiol 2010;109:221-31.

20 Eastwood A, Sharpe K, Bourdon PC, et al. Within subject variation in hemoglobin mass in elite athletes. Med Sci Sports Exerc 2012;44:725-32.

21 Wilber RL, Stray-Gundersen J, Levine BD. Effect of hypoxic 'dose' on physiological responses and sea-level performance. Med Sci Sports Exerc 2007;39:1590-9.

22 Rasmussen P, Siebenmann C, Díaz V, et al. Red cell volume expansion at altitude: a meta-analysis and monte carlo simulation. Med Sci Sports Exerc 2013:45:1767-72.

23 Garvican L, Martin D, Quod M, et al. Time course of the hemoglobin mass response to natural altitude training in elite endurance cyclists. Scand J Med Sci Sports 2012;22:95-103.

24 Gore C, Craig N, Hahn A, et al. Altitude training at $2690 \mathrm{~m}$ does not increase total Haemoglobin mass or sea level $\mathrm{VO}_{2 \mathrm{max}}$ in world champion track cyclists. J Sci Med Sport 1998;1:156-70.

25 Gough C, Sharpe K, Garvican L, et al. The effects of injury and illness on haemoglobin mass. Int J Sports Med 2013;34:763-9.

26 Kalantar-Zadeh K, Block G, McAllister CJ, et al. Appetite and inflammation, nutrition, anemia and clinical outcome in hemodialysis patients. Am J Clin Nutr 2004;80:299-307.

27 Ashenden M, Sharpe K, Habel J, et al. Improved alignment of reticulocyte counts between Sysmex XT-2000i instruments. J Clin Pathol 2013;66:232-7.

28 Pottgiesser T, Garvican LA, Martin DT, et al. Short-term hematological effects upon completion of a four-week simulated altitude camp. Int I Sports Physiol Perform 2012;7:79-83. 